\title{
Analysis of the modalities of return of populations to the contaminated territories following the accident at the Fukushima power plant
}

\author{
Pascal Croüail ${ }^{1, *}{ }^{*}$, Thierry Schneider ${ }^{1}$, Jean-Christophe Gariel ${ }^{2}$, Masaharu Tsubokura ${ }^{3}$, Wataru Naito ${ }^{4}$, \\ Makiko Orita ${ }^{5}$ and Noboru Takamura ${ }^{5}$ \\ ${ }^{1}$ Nuclear Protection Evaluation Centre (CEPN), Fontenay-aux-Roses, France. \\ 2 Radiation Protection and Nuclear Safety Institute (IRSN), Fontenay-aux-Roses Cedex, France. \\ 3 Minamisoma Municipal General Hospital, Minamisoma, Japan. \\ ${ }^{4}$ National Institute of Advanced Industrial Science and Technology (AIST), Tsukuba, Japan. \\ 5 Nagasaki University, Nagasaki, Japan.
}

Received: 1 April 2020 / Accepted: 21 April 2020

\begin{abstract}
Based on gathered viewpoints from Japanese stakeholders who face the consequences of the Fukushima Daiichi nuclear disaster at the national and local levels, the modalities and conditions governing the decision of evacuees to return home after the lifting of evacuation orders, have been examined. This analysis revealed the complexity of the situation in a context of high uncertainty, and also emphasized the need for decision-makers and decision-helpers (e.g. radiological protection and medical experts) to take account and respect the different choices made or envisaged by the impacted communities for whom radiological issues are only one facet of the problem. The analysis firstly deals with the dynamics of the emergency evacuation which has strongly influenced the issue of managing the return of populations. Social and especially family dimensions are also emphasized, particularly related to the organization of temporary housing. Then, the organization and the evolution of the characterization and zoning of the affected areas are discussed as well as the radiological criteria that have been used and how they have been perceived by people. Notably, the effects on health and welfare are emphasized, by analysing in particular the temporal dynamics since the accident. The difficulties encountered by evacuees and returnees and the specific situations of the various communities are also highlighted. The question of the development of a radiological protection culture through self-monitoring and protective actions and its long-term role is also discussed. Another key element concerns the effects of the compensation system: without going into details on the mechanisms put in place, the social and ethical questions raised by this system are presented. Finally, the question of "the future of the affected territories" is evoked by stressing the concerns of several municipalities for restoring their attractiveness for possible newcomers.
\end{abstract}

Keywords: nuclear accident / management / Fukushima / evacuation and return / health and well being

\section{Introduction}

The conditions for the return of populations to the territories evacuated after the Fukushima Daiichi Nuclear Power Plant(FDNPP) accident raise a certain number of questions in the context of post-accident management. The analysis of the situation reveals the complexity of the individual and collective decision-making processes. It shows that the radiological situation of the affected territories is only

\footnotetext{
*Corresponding author: pascal.crouail@cepn.asso.fr

${ }^{a}$ Present adresse: 28, rue de la Redoute, 92260 Fontenay-aux-Roses, France.
}

one dimension of the problem that individuals and communities are facing.

This article reminds the circumstances of the evacuation which has strongly influenced the issue of managing the return of populations in the Fukushima prefecture. The social and more particularly family dimensions are also addressed, particularly in relation to the organisation and duration of temporary housing. Next, lessons are proposed of the organisation of zoning, radiological criteria and health effects, with a particular attention of the temporal dynamics from the early phase of the accident of 11 March 2011 to the lifting of evacuation orders. In this context, testimonies collected from semi-structured interviews conducted during the study highlight the difficulties encountered by the population in 
making choice to return home or not. The question of the development of the radiation protection culture and its role in the long term is also introduced. A key element that emerges concerns the beneficial and adverse effects of the compensation system. In addition, the question of the future of the affected territory is evoked with the concerns expressed by several municipalities and the possibility of restoring their attractiveness for new inhabitants. Taking into account the feedback experience of the post-accident management of the FDNPP accident, this article discusses some main lessons to be learned for improving the preparedness and the development of framework for post-accident management.

\section{Material and method}

The analysis provided in this article is the result of a qualitative research, largely based on semi-structured interviews (Bernard, 2006) carried out with various Japanese stakeholders and actors of the rehabilitation strategies met by the authors since 2013. This method was selected with the aim to favour direct dialogue and interaction with the people concerned by this issue of the return of population following the first lifting of evacuation orders. A wide range of different decision makers and various interested parties including citizens involved in radiological protection, public health, agriculture and industry recovery have been interviewed. This includes in particular national authorities (Cabinet Office Support Team for Residents Affected by Nuclear Incidents in Tokyo) and their local counsellors in Kawauchi and Naraha, the local authority (Fukushima Prefecture: Public Health and Welfare Commission, Business Resumption Office, Decontamination Information Plaza, etc.), companies involved in rehabilitation and decontamination (TEPCo, JV), mayors and other elected people of several municipalities (Hirono, Kawauchi, Iitate), representatives of the Chambers of Commerce of Tomioka and Kawauchi, academics (Universities of Fukushima and Nagasaki), local NGOs and cooperatives (e.g. the Nouminren Association for the Defence and Support of Breeder Families in Nihonmatsu, the OIDE Support Centre for voluntarily evacuated families in Yonezawa, the Coop Fukushima), and residents including both evacuees and returnees (farmers, business owners, parents, retired persons).

The queries asked during 42 interviews conducted between 2015 and 2017 covered various topics such health and environmental monitoring, radiological protection issues, the pursuit of countermeasures in particular decontamination and management of associated wastes, the meaning and understanding of regulatory criteria used for the evacuation and return, and the living conditions of inhabitants (i.e. former residents as well as returnees). The analysis also considers testimonies shared in the context of the 20 dialogue meetings organized in the framework of the Dialogue Initiative undertaken by the International Commission on Radiological Protection (ICRP) since Fall 2011. The meetings were largely attended by residents of the 12 municipalities concerned by the evacuation orders allowing them to express their concerns (Kotoba, 2015; Lochard et al., 2019).

The survey was completed by a bibliographic analysis on issues relating to the modalities of return of the evacuated people. The results of the analysis have been presented and discussed during several meetings in Japan and in France in 2018 and 2019.

\section{Context}

During the emergency phase (i.e. between March and the end of September 2011), evacuation and sheltering measures were implemented on the basis of a criterion of distance from the Fukushima nuclear power plants (IAEA, 2015):

- for the evacuation: 2 then $3 \mathrm{~km}$ on March 11; 10 then $20 \mathrm{~km}$ on March 12;

- for the sheltering and containment of the non-evacuated population: $10 \mathrm{~km}$ on 11 March and $30 \mathrm{~km}$ on 15 March.

In the end, all the municipalities of Futaba, Okuma, Tomioka and parts of the cities of Namie, Minamisoma, Naraha, and Kawauchi were included in the compulsory evacuation radius $(20 \mathrm{~km})$. On April 11, based on projected estimates of the external doses that could be received by their inhabitants, two new zones were created, including the territories in the $20-30 \mathrm{~km}$ zone ("areas prepared for emergency evacuation": Tamura, Kawauchi, Hirono and part of Minamisoma) and even beyond $30 \mathrm{~km}$ ("areas prepared for deliberate evacuation" in Iitate, Kawamata, Minamisoma (Odaka), Namie and Katsurao. In these two areas, it was estimated that individual doses could exceed $20 \mathrm{mSv} / \mathrm{year}$ without a quick implementation of countermeasures (e.g. decontamination). It should be noted that the choice of this value of $20 \mathrm{mSv}$ /year as a cut-off value (NERHQ, 2011) was in line with the recommendations published by the ICRP, recommending a value of between 20 and $100 \mathrm{mSv}$ to manage "emergency exposure situations" (ICRP, 2007). In practice, the Japanese authorities used a derived criterion (i.e. $3.8 \mu \mathrm{Sv} / \mathrm{h}$ ) to delineate the evacuation areas (the calculation of the reference dose rate is based on a house occupancy time of $16 \mathrm{~h} / 24 \mathrm{~h}$, a protection factor of $40 \%$ and an averaged ambient dose rate background of $40 \mathrm{nSv} / \mathrm{h}$ before the accident).

Decontamination activities, implemented following the FDNPP accident, were completed in the so-called Special Decontamination Area (SDA, see Fig. 1) at the end of March 2017 (except in the "areas where returning is difficult"). After decontamination and thanks to radioactive decay, air dose rates have decreased by about $70 \%$ in residential areas and farmlands, about $60 \%$ on roads and $50 \%$ in forests (Shinkawa, 2019). At present, in most living places ambient dose rates are of the same order of magnitude as many places worldwide. According to "market basket" surveys performed in 2018 in different regions, the effective ingestion dose from radioactive caesium in food used in typical local meals has been estimated as being about $1 \mu \mathrm{Sv} /$ year or less and continues to decrease. Since 2012, the Maximum Permitted Level is $100 \mathrm{~Bq} / \mathrm{kg}$ for general food, $10 \mathrm{~Bq} / \mathrm{L}$ for drinking water, and $50 \mathrm{~Bq} / \mathrm{kg}$ for milk and infant food. Very few violations $(<1 \%$ before shipment; $<0.1 \%$ after shipment) of these Japanese standards have been observed since 2014, but only for game meat, freshwater fish, and wild edible plants (mushrooms, sansai) (Yokoshima, 2019).

As of April 2020, evacuation orders had been totally lifted in Hirono, Naraha, Kawauchi, Tamura, Katsurao, Kawamata, Date city, and partly in Minami-Soma, Iitate, Namie and 


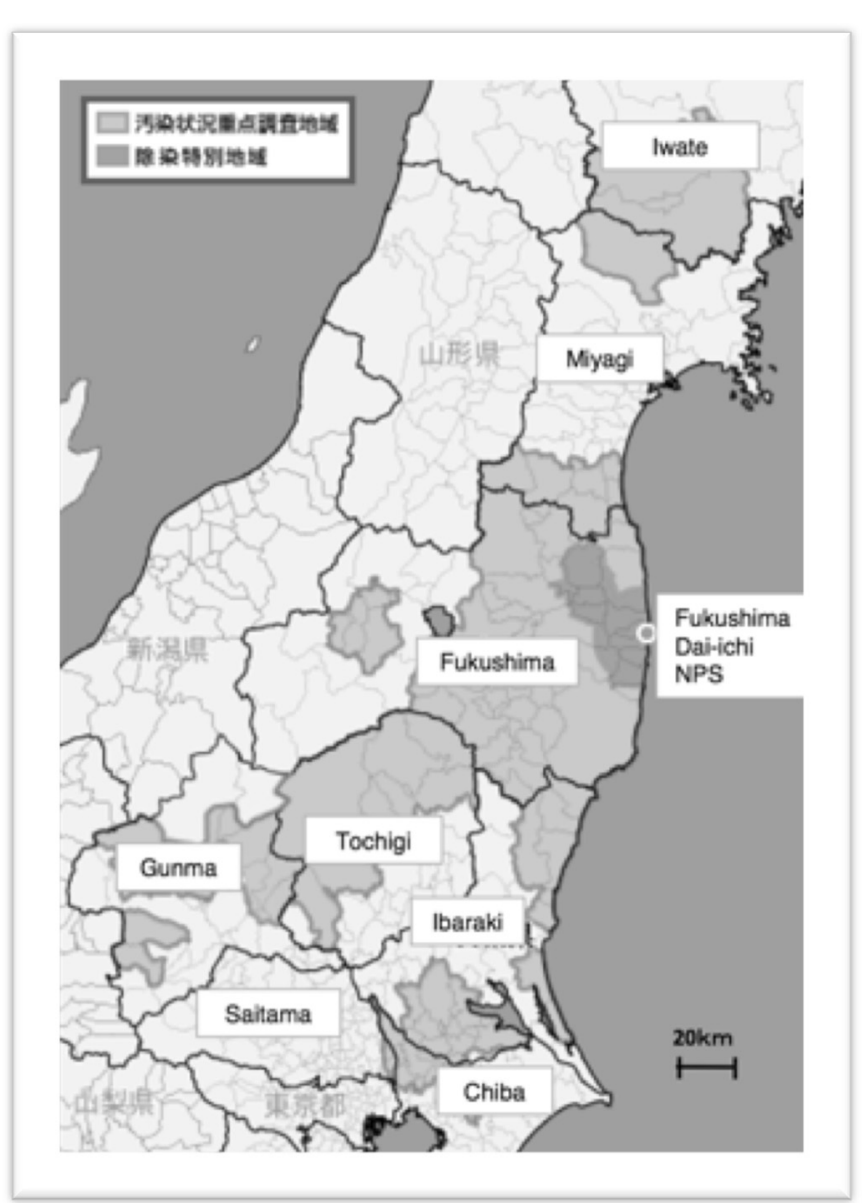

Fig. 1. SDA: Special Decontamination Area (dark grey) and ICSA: Intensive Contamination Survey Area (grey).

Tomioka. Returning is still considered difficult by Japanese authorities in the municipalities of Futaba and Okuma. Restoration of transport infrastructures, such as roads and railway, are making steady progress: the Joban expressway and national road $n^{\circ} 6$ reopened in 2014, and only one section - Namie to Tomioka - of the JR Joban railway line reopened on the 14th March, 2020. In previously evacuated areas, many public facilities and infrastructures, such as schools, medical service (hospitals, clinics, nurseries), shopping malls, etc. are reopening one after another. Some traditional festivals and religious events have also resumed.

Now, the Japanese government promotes and supports the "Fukushima Innovation Coast Scheme" with new priority areas for the Fukushima Prefecture such as decommissioning (mock-up test facility), research on robotics and drones, combined-hydrogen, wind, photovoltaic-energy production (concept of "smart cities"), and modern agriculture.

However, despite these significant reconstruction efforts, and encouraging results in terms of dose and risk reductions, it was observed that the number of registered returnees was quite low, several months after evacuation orders were lifted and that most returnees are elderly persons (Shinkawa, 2019). By early 2020 , no more than $20 \%$ of the former evacuees have returned home.

\section{Feedback}

\subsection{The evacuation of affected areas}

The chronology of the orders issued between March and September 2011 concerning sheltering, evacuation and protection (e.g. restrictions on the consumption of food or tap water), their varying nature (obligation vs. simple recommendation), their duration and term, the areas of application as well as their successive evolutions of the framework (Cabinet Office, 2012) gave the population the feeling of improvisation of postaccident management by the local or national authorities (Hasegawa, 2013). The Independent Investigation Committee of the Japanese Parliament also emphasized the unpreparedness of both the authorities and the Japanese population for the evacuation and emergency precautions and measures to be taken in the event of a nuclear accident (Kurokawa et al., 2012). As a matter of fact, the Japanese population had never been involved in preparedness exercises and had very little information on what to do in the event of a nuclear accident (Hasegawa et al., 2016).

Table 1 shows the distribution of the number of inhabitants (residents) in the different emergency evacuation areas as of August 20, 2011.

In such a context, the evacuation of the population has been often chaotic (Hasegawa, 2013). Numerous testimonies report that the voluntary evacuees and the inhabitants of compulsory evacuation areas were sometimes directed to places more contaminated than their former living places, requiring successive re-evacuations that dispersed families and the village communities for weeks or months (Fukushima University, 2012; Hori, 2017). The late evacuation of municipalities heavily affected by the radioactive deposits such as Iitate (placed in the "Deliberate Evacuation" Area on 22 April 2011) or the lack of action planed in other municipalities such as Date City (Nishida, 2014), undermined the credibility of the national authorities and generated both anger and anxiety among residents (Kurokawa et al., 2012).

On the other hand, the late evacuation of Iitate has probably saved lives among elderly people as it was finally decided by the mayor not to evacuate the nursing home: as a result, the death rate has not increased in this facility, unlike those that were evacuated on an emergency basis. (Tanigawa et al., 2012).

\subsection{Upheaval in the living conditions of evacuees, actual and potential health consequences}

The evacuees were temporarily relocated to several places inside and outside the Fukushima Prefecture in temporary housing complexes generally made up of a hundred independent air-conditioned bungalows that can decently accommodate 1 to 3 people at most, with a living area of less than $20 \mathrm{~m}^{2}$ and most often without private sanitary facilities. Although many efforts have been made by some municipalities (e.g. Kawauchi, Iitate, Naraha) to maintain the social link between evacuees (e.g. by continuing the publication of local newspapers, and organizing commemorative events, festivals and popular markets), the overall cohesion of the communities has been increasingly difficult to sustain, given the separation and 
Table 1. Number of persons evacuated from evacuation areas (as of 20 August 2011).

\begin{tabular}{|c|c|c|c|c|}
\hline City of origin & "Restricted" area & "Deliberate evacuation" area & $\begin{array}{l}\text { "Evacuation-prepared in } \\
\text { case of an emergency" area }\end{array}$ & No. of evacuees \\
\hline Okuma & $\sim 11500$ & & & $\sim 11500$ \\
\hline Tomioka & $\sim 16000$ & & & $\sim 16000$ \\
\hline Namie & $\sim 19600$ & $\sim 1300$ & & $\sim 20900$ \\
\hline Iitate & & $\sim 6200$ & & $\sim 6200$ \\
\hline Kawamata & & $\sim 1200$ & & $\sim 1200$ \\
\hline Tamura & $\sim 600$ & & $\sim 4000$ & $\sim 600$ \\
\hline Naraha & $\sim 7700$ & & $\sim 10$ & $\sim 7710$ \\
\hline Minamisoma & $\sim 14300$ & $\sim 510$ & $\sim 47400$ & $\sim 61710^{*}$ \\
\hline Hirono & & & $\sim 5400$ & $\sim 5400$ \\
\hline
\end{tabular}

Source: National Diet of Japan NAIIC, 2012.

long-lasting remoteness of the inhabitants linked to the postponement of the lifting of evacuation orders in many areas. Once they were compensated, many of the forced evacuees bought a new house or rent an apartment in a new place. Many evacuated families had the opportunity to send their children to school institutions in the major cities of the region (e.g. Iwaki, Koriyama), whose reputation was generally much better than that of their living place had before the accident. The cultural, sports and leisure activities from which they were consequently able to benefit made return unlikely or at least undesirable for the youngest ones. A few years after the accident, people especially the younger generations have rebuilt their lives elsewhere and the vast majority of the temporary housing complexes accommodated people over the age of 70 (Fukushima University, 2012; Moriyama et al., 2019).

The evacuation has progressively changed the structure of the families separating the elders from their children and grandchildren, whereas three generations previously lived together (Tsubokura et al., 2014; Wada, 2015). The length of stay in temporary accommodation seemed to many evacuees to be endless or even irretrievable because their house had been destroyed or too much degraded by the effects of the earthquake and tsunami or the prolonged abandonment.

Because the temporary accommodation was too small oldest evacuees rarely had occasions to see their family and relatives. Elderly people interviewed express feelings of isolation from family, loneliness and longing for their homeland. Moreover, many evacuees have complained of suffering stigmatization at the evacuation site where they were suspected of being contagious, sometimes not allowed to bathe in public baths or to donate blood, envied because of the compensation received, their children excluded by their classmates, etc. The elected officials interviewed (Kawauchi, Iitate, Hirono) pointed out that his break-up of village communities was and is still a major obstacle to reconstruction and revitalisation, particularly in the rural sector, where families were interdependent and very supportive prior to the accident.

As a feedback from the Hanshin-Awaji earthquake in 1995, attempts were made to move people from the same evacuation zone to the same temporary housing. Gathering people with similar characteristics and personal histories allowed to gradually rebuild social connections between evacuees. Especially for the elderly, after many moves that each of them had been forced to make, the relocation in temporary houses has sometimes been experienced as a life-saving experience as it has enabled the partial re-formation of neighbourhood communities that had been scattered during the emergency phase (Gill, 2013). The reunification of these people, close to their native land and the graves of their ancestors, was often experienced as a relief (Bennett, 2015).

Medical personnel (general practitioners, psychologists, dentists, nurses, etc.) come to consult the occupants of temporary housing complexes, periodically. Year after year, infrastructure to facilitate daily life (grocery store, small shops, games and gymnasiums, library) have been created nearby (with a free transport service), or even on site, in common buildings. Some of them were built nearby or in large cities (Iwaki, Koriyama, Fukushima, etc.), which for some evacuees also acted as a brake on their early return (i.e. before the temporary re-housing area was permanently closed), as access to medical care services and shops was much easier (Bruch, 2017). In the end, the return to a new house, in a neighbourhood emptied of its former inhabitants, was sometimes perceived as a second evacuation and shocking experience by the elders.

Soon after the FDNPP accident, an exhaustive health surveillance (health check-ups, Whole Body Counting, ultrasound thyroid examinations, etc.) has been implemented. Because most of the dose levels are low in terms of external doses (Tsubokura et al., 2015; Miyazaki and Hayano, 2017; Tsubokura et al., 2017; Nomura et al., 2019) as well as internal doses $(99.9 \%$ of the whole body counting measurements carried out are below the detection levels: $400 \mathrm{~Bq}$ for an adult and $50 \mathrm{~Bq}$ for an infant measured by Baby-Scan ${ }^{\circledR}$ ) (Miyazaki et al., 2014; Hayano et al., 2015), it is not expected that the Fukushima will have measurable outcomes in terms of radiation-induced diseases (e.g. cancers). As far as the large-scale ultrasound thyroid screening is concerned, experts now consider that it has provided little benefit to the patients, 


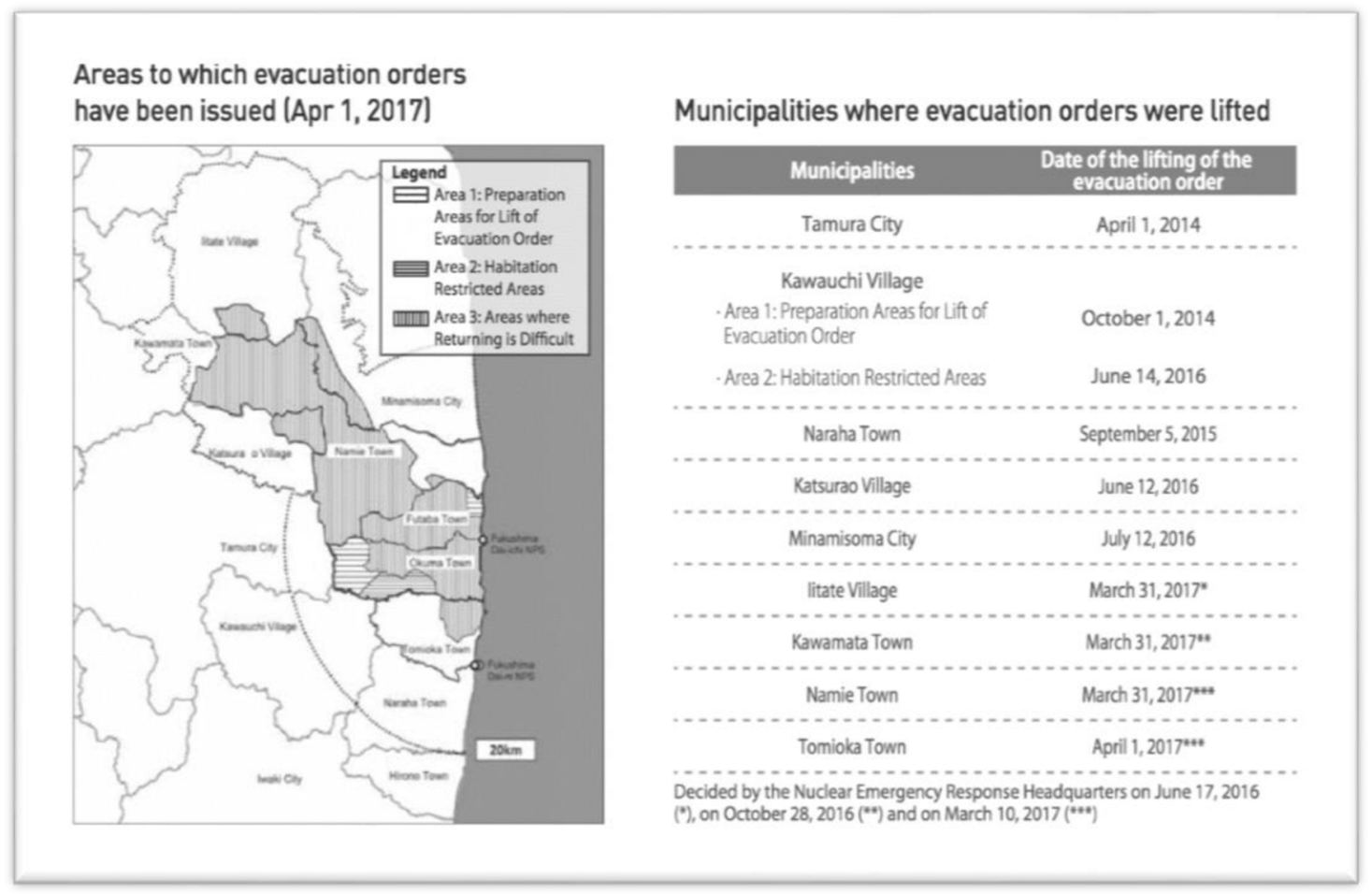

Fig. 2. Zoning status of affected territories (as of April 1, 2017) and dates of lifting of evacuation orders.

but has caused considerable distress and anxiety in the population (Oughton et al., 2016; Midorikawa et al., 2017), although there is a need to consider the contribution of this programme to respond to the expectation from the population to get a significant health surveillance.

The controversies among experts about the interpretation of post-Fukushima epidemiological and risk assessment studies are often relayed by the media without further clarification. These differences in appreciation of the radiological risk over the long-term have made fundamental life choices difficult within evacuees' families (Horikawa, 2016; Mosneaga et al., 2016): to leave or stay? Returning home or not? To have children in a contaminated territory or not? To build a new life elsewhere? To abandon the land of ancestors? So many discussions and dilemmas hotly debated within the families of evacuees with sometimes tragic consequences on their social life, mental health (Orui et al., 2019) and well-being (Moriyama et al., 2019).

Undoubtedly, there are many indirect victims of the FDNPP accident due to uprooting, family breakdown and/or job loss (more than 2000 cases of indirect deaths -e.g. depression, suicide - are considered to be disaster-related by the end of 2017) (Hasegawa et al., 2016). The precarious conditions in which evacuees had to live led to excess mortality among the elderly and has caused serious psychological consequences (Yasumura et al., 2012; Nomura et al., 2013; Murakami et al., 2019).

Because of the deterioration of their living conditions during the evacuation period, other non-radiation-induced health effects have been observed in cohorts of evacuated inhabitants, especially diabetes (Fukushima Health Management Survey Group, 2019); the degradation of several health effects indicators (body weight, body mass index, systolic and diastolic blood pressure, blood glucose levels, and triglyceride levels) has been reported (Ebner et al., 2016; Murakami et al., 2017; Zheng et al., 2017). This kind of secondary health issues have been also diagnosed in non-evacuated populations that live not in but close to evacuated areas (Tsubokura et al., 2014; Tsubokura, 2018).

The family cohesion also suffered from the side effects of the compensation system, which generated inequalities between its members. Each person evacuated has received about $€ 70000$ at the end of the 7 years of compensation for moral prejudice (at a rate of approximately $€ 800$ /month). Since April 2018, evacuees who lived in a place where the evacuation order had not yet been lifted at that moment are eligible to receive a lump sum of approximately $€ 100000$. Property damages were also compensated, at a rate depending on the location of the property and in proportion with the duration of the forced evacuation. Additional compensations were also paid for job losses, loss of income or productions, and extra works for implementing countermeasures. It should be noted that these compensations are much higher than those usually provided in Japan after natural catastrophes. This indemnification framework mainly depends on the zoning established in 2012 and the date when the evacuation order was lifted (Fig. 2): therefore, two families who were yet neighbours before the accident may have received compensation ranging from 1 to 10 . Feelings of injustice and inequity, envy and jealousy, social, inter- and intra- family disruptions are immeasurable and irreversible.

The compensation rules are therefore often perceived as unequal and unfair, notably because they do not sufficiently take into account the evolution of individual social and local 
economic situations before and after the accident. Farmers, for example, whose properties have not been included in the SDA often produce blindly (no measurement of contamination is made in their fields) and at loss because they suffer the degradation of the image of their products stamped by consumers "made in Fukushima".

Subsequently, after the evacuation orders had been lifted, the necessary works prior to return (refurbishment, clean-up) being taken care of and managed on a case-by-case, household-by-household basis, made it impossible for all the inhabitants to return collectively and concomitantly. After return, social connections were disrupted again, because the former evacuees moved to separate new residencies. Some residents started to say that life was actually better in temporary housing because social assistance and access to care were more readily available than in their new but isolated houses. It has to be noted that recent studies suggest that suicide rate is increasing in the population of returnees (Orui et al., 2019).

\subsection{Criteria for lifting the evacuation orders}

Once the authorities have declared the return of the plant to a safe state, and after additional measurements of ambient dose rates and measurements and estimates of radioactive deposition on the ground, access restrictions have been eased in most municipalities. A specific post-accident zoning of the affected territories was gradually established between July 2012 and August 2013 in the entire perimeter where evacuation orders were previously issued (Cabinet Office, 2012). The following areas were defined:

- Green areas where evacuation orders were ready to be lifted and where annual effective doses should not exceed $20 \mathrm{mSv}$ per year;

- Orange areas qualified as "restricted-residence" areas where only occupational activities and daytime residence were authorized, since the individual annual effective dose of a resident would be between 20 and $50 \mathrm{mSv} / \mathrm{year}$ in the event of permanent residence;

- Red areas qualified as "difficult-to-return" areas, where the return of residents is not possible "for a long time" (and probably not before March 2016), the annual doses being likely to exceed $50 \mathrm{mSv} /$ year.

In order to lift evacuation orders, intensive decontamination operations have been implemented in all these areas, with a priority given to green and orange areas (MOE, 2013, 2014). Consequently, the agenda of the return of the population had been mainly constrained by the completion of the decontamination operations, the planning of which being based on the abovementioned zoning. It has to be noted that many other countermeasures (e.g. in the agricultural sector) were and remain highly dependent on the zoning established in 2012; this is also the case for compensation issues, as well as the prioritization of rehabilitation actions and budgetary allocations for the reactivation of infrastructures, and the reconstruction and economic revitalization of the affected territories.

As the budgets are allocated on a case-by-case basis by the government through the Prefecture, the municipalities did not progress at the same pace in the rehabilitation process; this has sometimes created tensions between them or between village communities within a municipality ( $c f$. the case of Nagadoro, the only hamlet located in a red zone in the municipality of Iitate). Tensions also appeared between members of the same family who are not treated in the same way depending on whether they lived in this or that area of the municipality before the accident. The unity and resilience of the territory have been severely degraded by the division of each affected municipality into three or four zones whose residents have been treated very differently. These "border effects" are generally very divisive and stigmatizing (Ando, 2015; Fassert, 2020): the resulting loss of cohesion of village communities is often presented as the major obstacle to the return of inhabitants who no longer envisage building a common future together.

Moreover, the zoning implemented in Fukushima Prefecture in 2012 has evolved slowly in time (Fig. A1) and space: evacuation orders are only lifted if the decontamination of a village (or an entire municipality) is fully completed (according to ambient dose rates criteria that guarantee that individual doses will be below $20 \mathrm{mSv} / \mathrm{y}$ ), if the main infrastructures (water, gas, electricity, means of transport and fuel, food shops, health and care facilities, schools, administrative services, etc.) are brought back into service and only after consultation of the local community. The evolution of the radiological situation (reduction of the ambient dose rate by radioactive decay and/or decontamination) is not sufficient to encourage the inhabitants to return. On the contrary, some residents of the evacuated areas do not understand why they are not allowed to return when dose rates are low all around and yet farming is allowed in the vicinity of their homes.

As mentioned above, the third condition prior to lifting an evacuation order is to take account the opinion of the population: as time goes by, the expectations and concerns of the inhabitants focus on living conditions, particularly in terms of employment prospects (a particularly sensitive issue for farmers and fishermen in particular), housing, education for their children, health care and more generally well-being. Many inhabitants would only consider returning if the rest of the evacuated population (e.g. shopkeepers, teachers, doctors and nurses, civil servants and entrepreneurs, former neighbours and friends, etc.) decided to return at the same time.

The Japanese Government has set $20 \mathrm{mSv} /$ year as a cut-off dose for people's return with a long-term target of $1 \mathrm{mSv} /$ year. In practice, derived reference levels i.e. ambient dose rates $(3.8 \mu \mathrm{Sv} / \mathrm{h}$ and $0.23 \mu \mathrm{Sv} / \mathrm{h}$ respectively) have been used. According to several studies, this approach was very conservative (Naito et al., 2017) and the communication to the public about the assumptions behind dose assessment has been probably insufficient (Shimura et al., 2015). As a matter of fact, values of the measured effective doses actually received by returnees were generally significantly lower than those calculated from ambient dose rates (Nomura et al., 2015; Naito et al., 2016; Miyazaki and Hayano, 2017).

Indeed, with no deadline announced for the end of the decontamination activities and no clear explanation as to the degree of conservatism in the calculations, the reference level of $3.8 \mu \mathrm{Sv} / \mathrm{h}$ was quickly perceived as too lax, particularly with regard to the radiation protection of children. While MEXT proposed reopening schools on the basis of this criterion, several associations (Parents in Fukushima, Japan Federation 
of Bar Associations, Japan Medical Association, etc.) strongly contested this option. The Japanese authorities had to lower the criterion for the clean-up of schools and public places that may be frequented by children (public parks, private gardens, streets, etc.) by proposing an ambient dose rate target of $0.23 \mu \mathrm{Sv} / \mathrm{h}$ ( $\sim 1 \mathrm{mSv} /$ year) (Takahara et al., 2017). But, achieving this level of ambient radioactivity has proven to be very difficult in many places. This has sometimes led many parents, who had voluntarily evacuated and then came back home (to Date City, Kawauchi, Minamisoma, etc.), to no longer allow their children to play outdoor, and according to medical studies, has contributed to childhood obesity (Zheng et al., 2017).

Decontamination work is entrusted to companies that are not necessarily specialists in measuring radioactivity in soils. These companies therefore usually use simplified methods to characterize the radiological situation, to assess the need for decontamination or to measure the effectiveness of their work (MOE, 2013). The criteria used are based on the measurement of the ambient dose rate (at ground level or at an altitude of $1 \mathrm{~m})$. In fact, when the companies in charge of decontamination communicate the results of their work to the public, they most often refer to this value $(0.23 \mu \mathrm{Sv} / \mathrm{h})$ rather than the official one $(3.8 \mu \mathrm{Sv} / \mathrm{h})$ (Murakami et al., 2015). As a consequence, most of the interviewed people report that they would return only if ambient dose rates in public places and around homes would be below the "benchmark" value of $0.23 \mu \mathrm{Sv} / \mathrm{h}$.

The additional efforts required to achieve such a level of residual ambient dose rates have generated considerable volumes of low-level contaminated waste, multiplying the storage of big-bags that are still visible in many places within the Prefecture of Fukushima. This situation is often considered prohibitive by local residents because the waste storages degrade the landscape and constitute a threat of further dispersion of radioactivity in the environment, as happened locally during floods in 2019.

Priority for characterization and decontamination actions were given in the perimeter of the SDA, where recovery operations are under the responsibility of the government. This choice has been strongly criticized by the actors of the agricultural sector: indeed, the authorities carried out few contamination measurements of the cultivated soils and communicated mainly on the dose rates in the air, which did not allow farmers to estimate whether or not they can resume their activity without taking the risk of producing, at loss, unsaleable items. Outside the SDA, decontamination works are led by the municipalities, each of which determines its own approach and priorities and the planning of decontamination work (Nishida, 2014).

The focus of the authorities and the population on the ambient dose rate levels can be explained by the very low levels of artificial radioactivity in marketed foodstuffs and as a consequence very low doses that could be received through ingestion by residents (Renaud et al., 2014; Maître et al., 2020). To date, only products of forest harvesting-mushrooms or sansai-edible wild plants - may be contaminated at levels that significantly and frequently exceed the maximum allowable levels. Even though vegetable and fruit growing are practised in Japan, the fact is that few people have returned to live in the evacuated areas, and no significant internal
Areas of concern cited by evacuees (\%, multiple choices) - (FU, 2012)

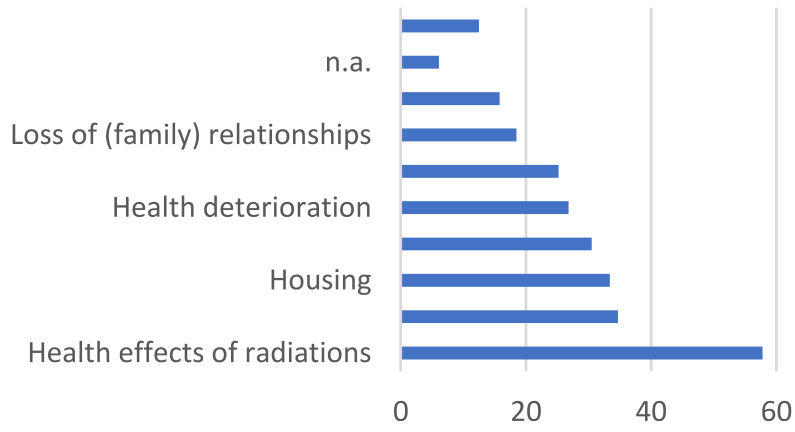

Fig. 3. Areas of concern cited by evacuees (Source: Fukushima University)

exposures through episodic consumptions of products from private gardens have been yet observed.

According to a survey conducted by the Fukushima University (Fukushima University, 2012), one year after the accident the radiological situation was cited by evacuees as their most important concern (see Fig. 3). But, three years after the accident, according to a survey conducted by the Reconstruction Agency in six municipalities - Kawamata, Tomioka, Okuma, Futaba, Namie and Iitate - (see Tab. 2) the reasons that explain their decision not to return was more governed by their living conditions (Reconstruction Agency, 2012-2019) than the radiological situation.

\subsection{Dynamics of return}

As indicated above, the evacuation of the affected areas resulted in the evacuation of approximately 146000 people (Tab. 1$)$, a bit more $(\sim 165000)$ having applied for the evacuee status one year after the accident (Fig. 4). Over time, the change in the number of residents of the municipalities affected by the evacuation orders is due to various factors: decision to return after the evacuation order is lifted, maintenance of the status of evacuee pending a decision, decision to become a resident of another municipality, or the person's death. Figure 4 shows the change in the number of evacuees between May 2011 and May 2019, based on data from Fukushima Prefecture, distinguishing between those still residing in the prefecture and those evacuated outside the prefecture.

It should be noted that the lifting of evacuation orders does not immediately result in a decision by the residents, who have about one year to make their own decision. Another factor to note is that retaining resident status when the evacuation order is not lifted allows individuals to receive compensation and benefit from exemptions from certain taxes that go beyond financial assistance for resettlement. Thus, for a certain number of people, even if their decision not to return is made, they can retain their status as evacuees. This is particularly true for those evacuated outside Fukushima Prefecture.

It should be noted that the termination of compensation in August 2012 for 58000 persons evacuated from the Emergency Evacuation Preparation Area did not result in a significant reduction in the number of evacuees as these persons were still eligible for housing assistance beyond the termination of 
Table 2. Results of an opinion poll of people evacuated from the municipalities of Kawamata, Tomioka, Okuma, Futaba, Namie and Iitate (based on Reconstruction Agency survey results, 2015).

Reasons given for choosing not to return if the evacuation order were lifted right now (multiple choice).

[Based on survey conducted by the Reconstruction Agency in 2015]

[Question: Why won't you return once the evacuation order is lifted?]

Absence or lack of medical infrastructure

Absence or lack of commercial infrastructure

Concern about the safety of tap water ${ }^{*}$

Deterioration or destruction of the house

Concern about the safety of nuclear power plants

Radioactivity, potential dose or ambient dose rates too high ${ }^{*}$

Daily life is more convenient at the evacuation site

Nostalgia for traditions, festivals, nature ("we're not going back to the way things were")

Lack of care services for the elderly [responses from the elderly].

Fear for loneliness (family, friends and former neighbours have left the area)

Absence or lack of transport infrastructure

Access to the former living place is now too difficult

Lack of job prospects

Lack of care services and nursing homes

School closure, lack of school or educational facilities

New life has begun ("I will not come back no matter how things will evolve")

School much better at the evacuation site

Concern about the safety of radioactive waste storage or disposal sites ${ }^{*}$

Loss of occupational (farming) activity

New job found at the evacuation site

Additional reasons

Loss of occupational (industry, trade) activity

Preference for the evacuation site

Might change mind

New home purchased

Risk of tsunami or earthquake in the future

Contamination of forests or rivers ${ }^{*}$

Presence of waste storage sites or ISF*

Number of responses out of 8775 respondents multiple answers

$\begin{array}{ll}5219 & 59 \\ 4813 & 55 \\ 4668 & 53 \\ 4366 & 50 \\ 4342 & 49 \\ 4308 & 49 \\ 3549 & 40 \\ 3403 & 39 \\ 3186 & 36 \\ 2860 & 33 \\ 2588 & 29 \\ 2456 & 28 \\ 2315 & 26 \\ 2294 & 26 \\ 1790 & 20 \\ 1587 & 18 \\ 1497 & 17 \\ 1315 & 15 \\ 1196 & 14 \\ 1172 & 13 \\ 1155 & 13 \\ 1154 & 13 \\ 1107 & 13 \\ 584 & 7 \\ 492 & 6 \\ 297 & 3 \\ 220 & 3 \\ 215 & 2\end{array}$

* Lines indicate reasons that are linked with radioactivity, radiological or radiation protection issues

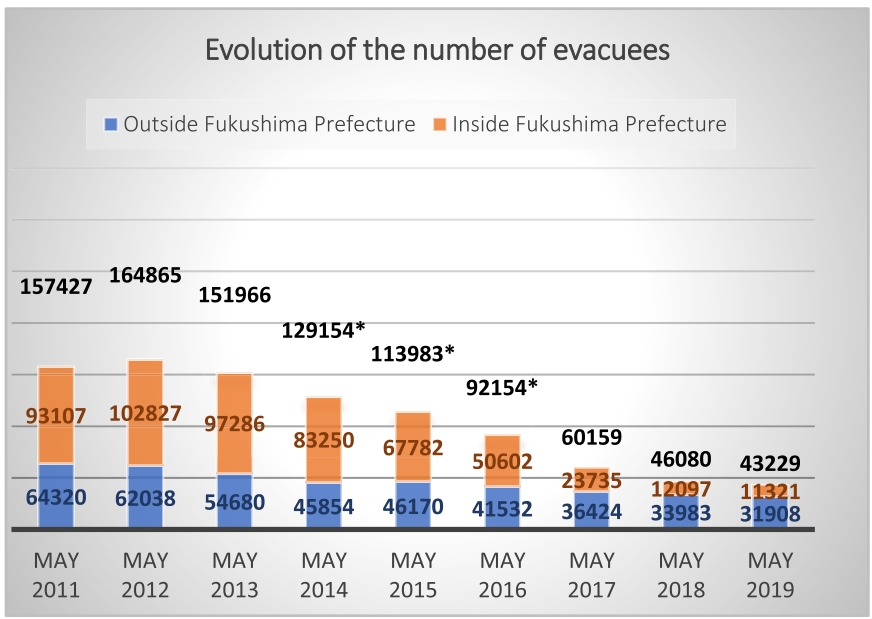

Fig. 4. Evolution of the number of evacuees (Source: Fukushima Prefecture, 2011-2019). ( ${ }^{*}$ includes evacuees to destinations that at the time were still unknown). Source of data: http://www.vill.iitate. fukushima.jp. compensation. On the other hand, the termination in April 2017 of housing assistance for 26600 people led to a significant reduction in the official number of evacuees. But, the reduction in the number of evacuees does not mean an equivalent increase in the number of people returning to their previous place of residence; this only reflects the decrease in the number of people who are recognized as evacuees by the government.

In municipalities where evacuation orders have been lifted, the return rate of evacuated residents is extremely low. Table 3 shows the situation as of December 2019.

According to a survey made in Naraha by the Reconstruction Agency in 2015-i.e. just after the evacuation order was lifted - it was observed that a little less than half of the population envisaged an imminent return, one fourth was still hesitating, and the last quarter had given up any prospect of returning. But, in fact, it was observed that one year after the evacuation order was lifted, less than $10 \%$ of the population had finally returned to live in the municipality and about a quarter, two years later. It is only in the course of 2019, that the population of Naraha reached $50 \%$ of the population censused in 2011 (Reconstruction Agency, 2012-2019). 


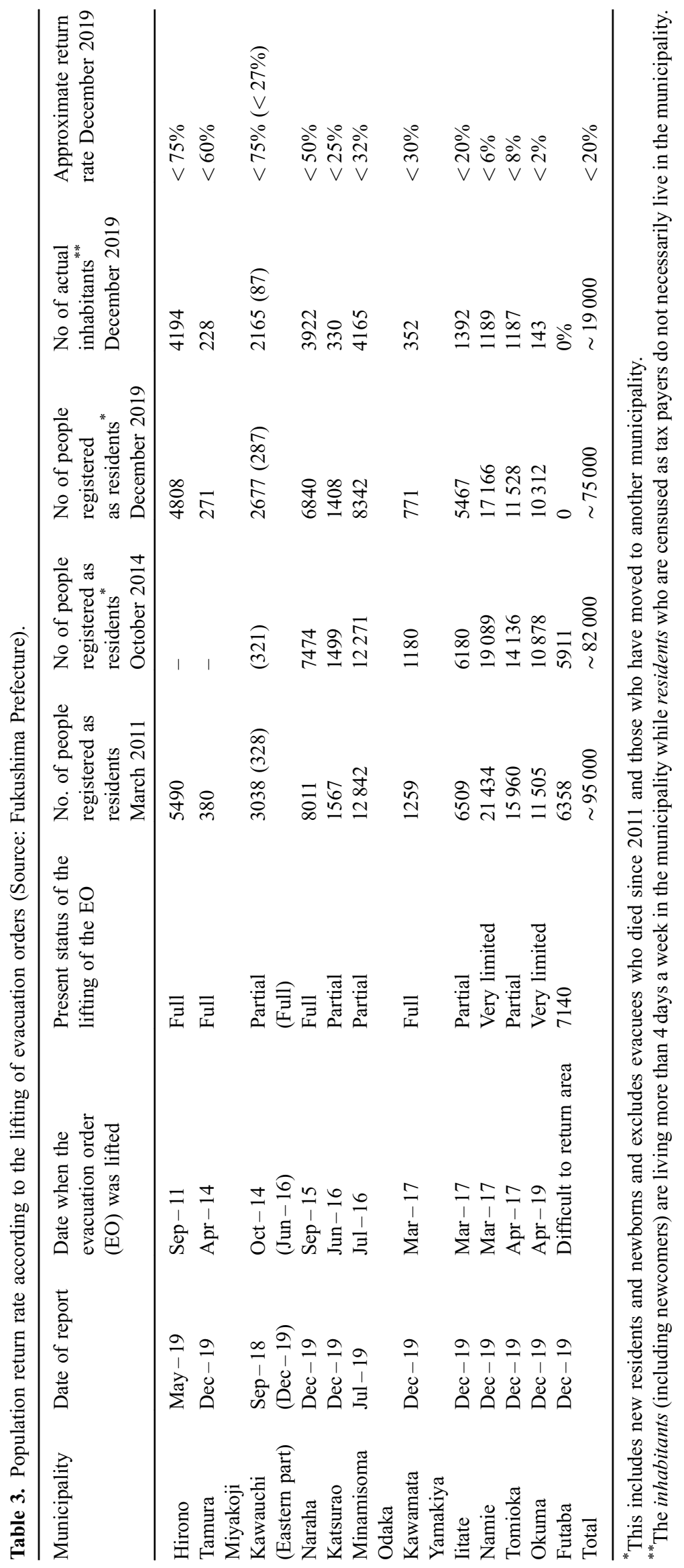




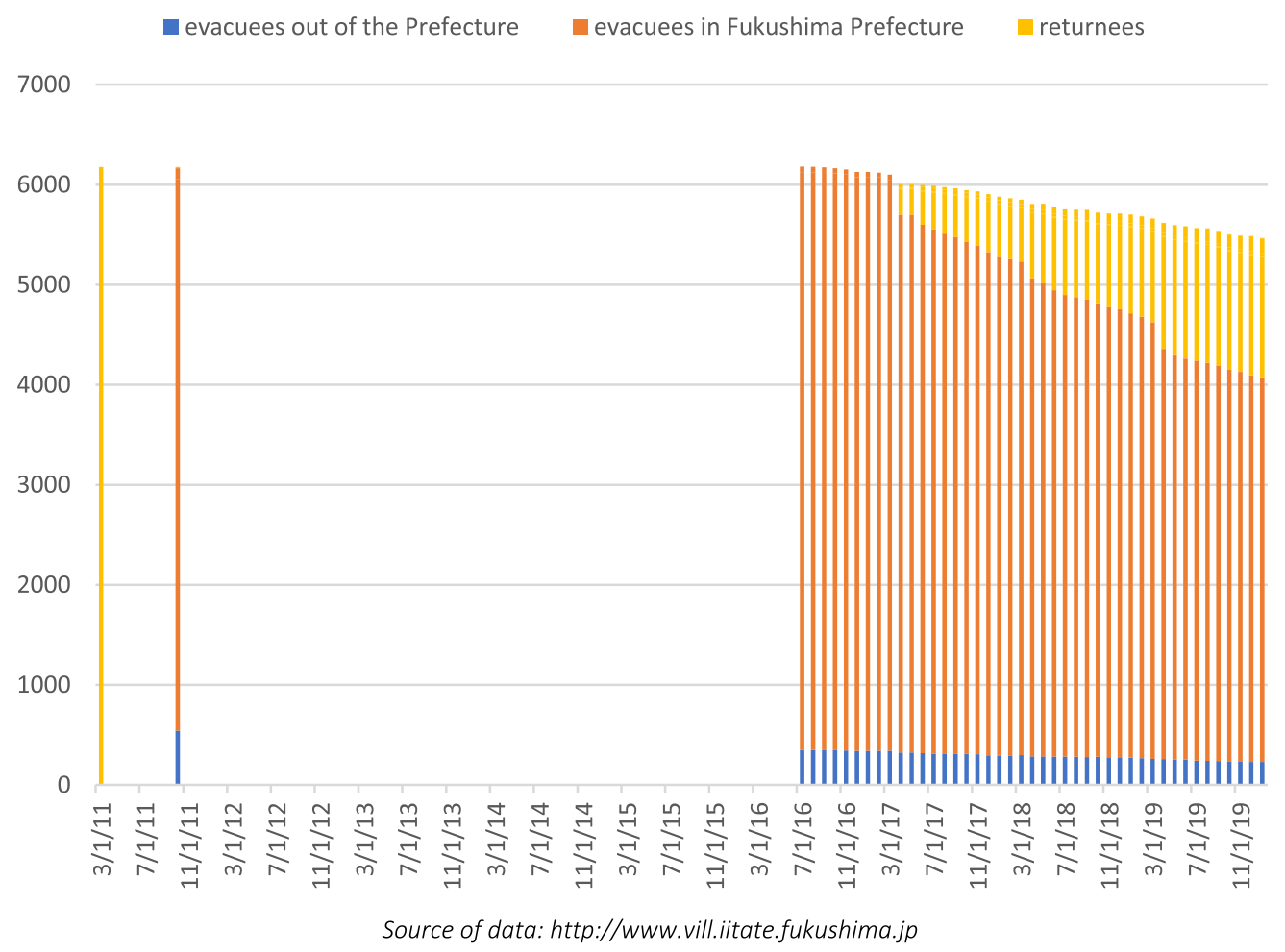

Fig. 5. Return of population in Iitate since the lifting of the evacuation order (EO) (as of 31 December 2019). Source of data: https://www.town. naraha.lg.jp and https://www.tomioka-town.jp.

The situation used to be even more critical in Tomioka where, there was only one child pre-registered for the start of the 2018-2019 school year following the lifting of the evacuation order in March 2017. These situations inevitably lead to an overall ageing population in formerly evacuated areas (Zhang et al., 2014).

The real rate of return of evacuees is difficult to evaluate because the municipalities do not report in the same way. Some of them publish the number of registered inhabitants including new residents and newborns, others report the inhabitants who actually live in the municipality 4 days a week (or more). Thus, it is difficult to follow the fate of the population that was initially evacuated (the identification of deaths and removals out of the Prefecture is almost impossible). Moreover, some residents are still registered in the municipality of origin as they pay taxes and work here but in fact, they live with their family elsewhere. Table 3 shows that more than 8 years after the accident the total return rate of people does not exceed $20 \%$. It should be also noted that the return rate is clearly correlated with the date of the lifting of the evacuation orders.

In January 2020 there are still "difficult-to-return" areas in five municipalities: Futaba, Okuma, Namie, Iitate, and Tomioka.

Figure 5 describes the dynamics of return in Iitate (number of evacuees $v s$. number of returnees since the lifting of the evacuation order in March 2017), and Figure 6 show the evolution of the population (including new residents) of Naraha and Tomioka where the evacuation orders were lifted in September 2015 and April 2017, respectively.

\section{Discussion}

There are many lessons to be learned from the management of the evacuation after the Fukushima Daiichi Nuclear Power Plant accident. Beforehand it must be remembered and pointed out that the evacuations were often made in bad weather conditions on roads heavily damaged by the earthquake and the tsunami. Electricity was cut off, accesses to critical infrastructures made very difficult; many residents had been personally affected by the catastrophe and had quickly left the area on their own initiative which made difficult to keep the rest of the population in place. In such a context, the evacuation was therefore speeded up, which may have made it sometimes chaotic.

The principle that should govern the evacuation is to do more good than harm. Therefore, it would be useful to plan in advance which facilities/establishments should or should not be evacuated very soon after the accident, how long could it take and how essential it is for hospitals, nursing homes, industrial plants that can't be easily shut down, etc. It should also be useful to anticipate the evolution from evacuation (during a few days) to temporary relocation (for longer periods from several weeks to several years). The planning of the temporary relocation of thousands of people at the same time has to be anticipated. Alternatives to evacuation, as prolonged sheltering, should also be considered in preparedness plans for the management of post-accident situations. As far as possible, successive movements of evacuees should be avoided and preference should be given to solutions that accommodate evacuees from the same locations in the same place. The 


\section{Evolution of the population in Naraha (EO lifted Sep-15)}

residents $>4$ days/week in Naraha

no.people registered as Nahara's citizens

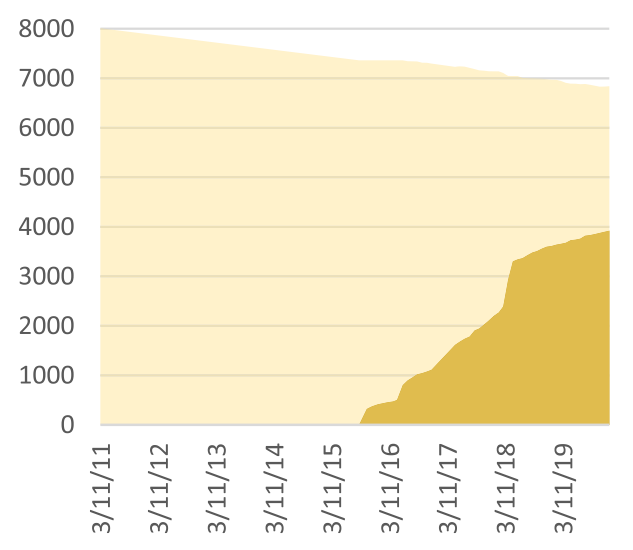

Source of data: https://www.town.naraha.lg.jp
Evolution of the population in

Tomioka (EO lifted Apr-17)

residents $>$ 4days/week in Tomioka

no. people registered as Tomioka's citizens

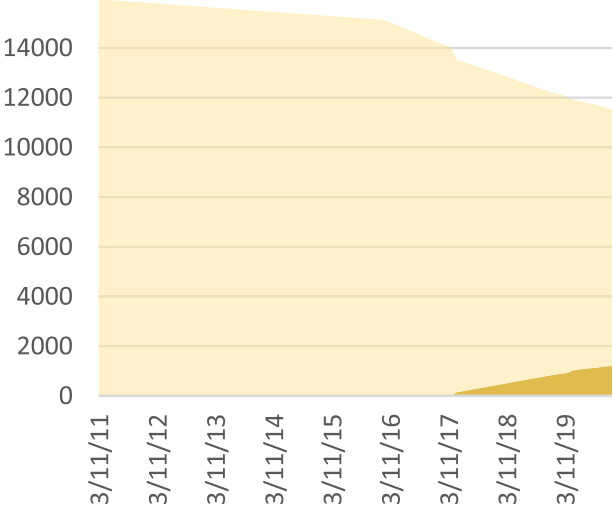

Source of data: https://www.tomioka-town.jp

Fig. 6. Return of population in Naraha and Tomioka since the lifting of the evacuation orders (as of 31 December 2019).

FDNPP accident has shown that the duration of temporary removal can be long (much longer than after natural disasters) which mean that a specific attention must be paid on living conditions during the relocation period. Especially, maintaining intra-community (municipality) links during that period is of outmost importance, as far as the return dynamic is built around communities of inhabitants.

It is estimated that about 300000 persons evacuated during the first weeks after the Fukushima nuclear power plant accident, half of them on a voluntary basis, the other half because their house was placed in the area that later became the SDA. After the post-accident zoning and the SDA were established in April 2012, about 150000 people had to wait for the lifting of the evacuation orders before to envisage their return. More than eight years after the accident, less than 20000 of them have actually returned home, option which is probably irrevocably compromised for the majority of the 24000 residents whose houses are still in the so-called "difficult-to-return areas".

This slow dynamic in return shows that it is very important to ensure transparency on the different steps towards temporary re-housing (and return home): in case of an accident, the competent authorities should first clearly communicate on the criteria used to decide on evacuation; in a second step, they should inform evacuees as soon as possible of the process to be put in place for lifting evacuation orders and authorizing return. In this perspective, it is important to prepare in advance the information messages that would be delivered to evacuees and to communicate on the multidimensionality and flexibility that have to be considered in the elaboration of the criteria to be adopted for the decision on the return. Particularly, the use of radiological-only criteria, not at all flexible, has shown limitations in a context of great uncertainty. It is obvious that authorities or governments could not impose return of evacuees but they have to create the conditions (information, consultation, dialogue, empowerment, and assistance) that make it possible in the respect of their autonomy and dignity.
The reconstruction and revitalization of the territories affected by the 11 March 2011 disaster will still take a long time. In this context, municipalities have difficulties forecasting their future and sizing infrastructure to accommodate the potential number of residents. The decision whether or not to return is a matter of choice and preference for each individual or family, and these choices must be respected. Municipalities are seeking to modernize infrastructure and develop economic activities in order to increase their attractiveness to their former residents but also to potential new residents in a changing territory. The temporality of return cannot be imposed: it is necessary to adapt to local dynamics and create the environment and framework for facilitating a return to dignified living and working conditions, and for accompanying the different personal choices, whether to come back or not.

Today, the recovery process is being reoriented towards the economic revitalization of the affected territories through the implementation of the Fukushima Innovation Coast Framework which is the top priority for Japanese authorities. It aims at encouraging people to return and attracting newcomers (building new housing, setting up businesses), to resume professional activities and by helping to set up new businesses (construction of new housing, large shopping malls, gas stations, development of high-tech industry: robotics factories, development of photovoltaics, biodiesel, and organic farming, etc.).

With regard to long-term health consequences, many questions emerge: what psycho-social support measures should be implemented for families wishing to return? Many worrying subjects, often raised in inhabitants' concerns remain unanswered: what is the risk of over-accidents or leaks at the Fukushima-Daiichi power plant, what is the fate of the waste from decontamination and the future of the ISF (Interim Storage Facility), what will be the levels of exposure in the non-decontaminated areas? It should be useful to further consider the structures for dialogue to be set up to discuss with a population, legitimately concerned about the evolution of the 
situation, and to question the behaviours to adopt in order to live on contaminated territories with the appropriate level of vigilance.

Efforts have been made by local governments, municipalities and scientists to inform the public about radiological protection issues. For instance, it should be pointed out that many popular and informative books on radioactivity and practical radiation protection have been published by local authorities and universities. Many are made available to the public in the form of booklets in health centres, schools, town halls, or in specially created places such as Decontamination Information Plaza (renamed Environmental Reconstruction Plaza) in Fukushima City. It is difficult to measure the public interest for this type of information, but it has the merit of existing. In any way, the FDNPP accident showed that the radiation protection culture in the modern societies is poor and therefore deserves to be strengthened, both in preparedness and after an accident occurs. In Japan, many people met expressed their fear about radioactivity, their lack of knowledge of the long-term health effects of ionizing radiation, or their desire to better understand or personally participate in the radiological characterization of their territory (by measuring individual doses, for example) in order to better understand the radiological situation. These are actions that can be promoted in preparedness stage through citizen science projects (Bertho et al., 2019).

In all these areas, the role of expert (in health, radiation protection, social science, economy, environment, etc.) is crucial but it should be recognized that few of them are really prepared to act in this perspective (Gariel et al., 2018; Schneider et al., 2019). In Japan for instance, only a few scientific expertise institutes are present and active in the areas that had been evacuated. Most of them are focused on the technical management of the accident: decommissioning of the plant, decontamination, communication on environmental measures (in particular air dose rates) or decontamination work. Very few are involved in the accompaniment of persons who are candidates for return, or who have already returned. The "counsellors" who have this function are most often from the university environment (Fukushima Medical University, Universities of Fukushima, Nagasaki and Hiroshima, etc.) or from environmental NGOs. While they are all aware that their role is important and that vigilance should be maintained over the very long term, they are too few in number and, by their own admission, tired and weary after years of accompanying the evacuated populations (Oughton et al., 2016). Training the experts and elaborating a framework to create the conditions for the experts to participate to the recovery process at the service of the population would be certainly a key feature for interacting with people affected by a nuclear accident.

\section{Conclusion}

The FDNPP accident was marked by preventive evacuation decisions and the establishment of a specific affected area zoning following radioactive fallout in the territory. For the first time, this dynamic of population displacement raises the question of how to organize the return of populations by taking into consideration both the radiological and socio-economic dimensions and by respecting individual and collective decisions. In this context, temporal dynamics play an important role at several levels:
1 At the time of evacuation, it seems useful to take into account the following stages and to think about the decision-making processes that will make possible to foresee the return of the population; it is certainly not easy to predict the possible evolution of the situation but, nevertheless, the experience of the FDNPP accident shows the usefulness of thinking in particular about the setting-up of radiological criteria, taking into account their evolution over time;

2 Before making decisions on the evolution of zoning and the lifting of evacuation orders, it is important to take the time to consult and involve the various concerned stakeholders, as these decisions must take into consideration multiple factors that go far beyond radiological issues.

The analysis of the management of the return of the populations also emphasized the key role of the mechanisms for accompanying the populations both during the evacuation period and to enable the return to the affected municipalities. There is probably no ideal and perfectly fair compensation system, but a reflection during preparedness phase on possible indemnification and revitalization frameworks after nuclear accidents would undoubtedly be necessary. In addition to compensation, these mechanisms concern housing assistance, infrastructure development and support for previous or new and attractive economic activities, as well as the implementation of environmental and health monitoring to accompany the populations living in these territories. The dimensioning of these mechanisms is complex and plays a key role both in guaranteeing decent living and working conditions for people affected by the accident and in the choice of these people with regard to their future.

After the FDNPP accident, an environmental monitoring program for contamination was put in place. Its long-term future and its contribution to the organisation of vigilance is already being considered. The role of the radiation protection culture and its transmission to the younger generations is an issue that needs to be examined in greater depth. Similarly, the monitoring of the evolution of the health of the populations living in the municipalities where evacuation orders have been lifted will also be raised. To what extent will the structures that are being set up meet the expectations of these populations and what is the appropriate health monitoring to meet the challenges posed by life in these areas?

The analysis of the conditions of the return of the populations shows that one of the key elements concerns the capacity to restore a socio-economic dynamic in the municipalities following the lifting of evacuation orders. Each municipality is a particular case given the local specificities, the extent of the contamination, the activities impacted, the structure of the population having decided to return, etc. For some municipalities, the medium-and long-term socioeconomic dynamics will sometimes depend on the agricultural situation, on the capacity to attract new inhabitants, on the guarantee provided in terms of environmental management, or on the implementation of a joint project at the level of the region. In this context, it is essential to further consider the role of radiological protection to guarantee decent living and working conditions and to support socio-economic development projects while respecting individual and local community choices. 


\section{References}

Ando R. 2015. A line dividing people's lives. In: Second Asian Workshop on the Ethical Dimensions of the System of Radiological Protection, Fukushima Medical University, Fukushima City.

Bennett GW. 2015. Lessons from Fukushima: Relocation and recovery from nuclear catastrophe. Thesis, Naval Postgraduate School, Monterey, California.

Bernard HR. 2006. Research methods in Anthropology: Qualitative and quantitative approaches, 4th ed. Rowman Altamira.

Bertho JM, Maître M, Croüail P, Naito W, Shkliarava N, Mostovenko A, Jones K, Simon-Cornu M. 2019. Assessment of population radiation exposure at the edge of the exclusion zone 32 years after the Chernobyl accident: methods and preliminary results. Radioprotection 54(4): 247-257.

Bruch C. 2017. Barriers to long-term return after the Great East Japan earthquake: Lessons from Hirono Town. J. Asian Develop. 3(1).

Cabinet Office. 2012. Designating and rearranging the areas of evacuation. Japan: Cabinet Office Support Team for residents affected by nuclear accidents.

Ebner DK, Ohsawa M, Igari K, Harada KH, Koizumi A. 2016. Lifestyle-related diseases following the evacuation after the Fukushima Daiichi nuclear power plant accident: a retrospective study of Kawauchi Village with long-term follow up. BMJ Open 6: e011641. https://doi.org/10.1136/bmjopen-2016-011641.

Fassert C. 2020. L'accident nucléaire de Fukushima: enjeux et contestations autour de la définition du zonage. Radioprotection 55(1): 29-38.

Fukushima Health Management Survey Group. 2019. Evacuation is a risk factor for diabetes development among evacuees of the Great East Japan earthquake: A 4-year follow-up of the Fukushima Health Management Survey. Diabetes Metab. 45(3): 312-315.

Fukushima University. 2012. Post-disaster reconstruction survey in the Futaba district (Namie, Futaba, Okuma, Tomioka, Naraha, Hirono, Katsurao and Kawauchi). Fukushima University Disaster Reconstruction Institute (Saigaifukko).

Gariel JC, Schneider T, Rollinger F. 2018. The role of experts in post accident recovery: Lessons learnt from Chernobyl and Fukushima. Ann. ICRP 47(3-4): 254-259.

Gill T. 2013. Special Issue Practicing a public anthropology of the East Japan disaster. Radiation and responsibility: What is the right thing for an anthropologist to do in Fukushima? In: Japan copes with calamity: Ethnographies of the earthquake, tsunami and nuclear disasters of 2011 (Peter Lang, 2013).

Hasegawa R. 2013. Disaster evacuation from Japan's 2011 tsunami disaster and the Fukushima nuclear accident. Studies 2013(5). IDDRI.

Hasegawa A, Ohira T, Maeda M, Yasumura S, Tanigawa K. 2016. Emergency responses and health consequences after the Fukushima accident; evacuation and relocation. Clin. Oncol. 28: 237-244.

Hayano R, Tsubokura M, Miyazaki M, Satou H, Sato K, Masaki S, Sakuma Y. 2015. Whole-body counter surveys of Miharu-town school children for four consecutive years after the Fukushima NPP accident. Proc. Jpn. Acad. Ser. B Phys. Biol. Sci. 91(3): 92-8. https://doi.org/10.2183/pjab.91.92.

Hori A. 2017. Psychological situation of local residents in Fukushima after the complex disaster in 2011. Austin J. Emerg. Crit. Care Med. 4(2): 1058.

Horikawa N. 2016. Displacement and hope after adversity: Narratives of evacuees following the Fukushima nuclear accident. In: Unravelling the Fukushima disaster (M. Yamakawa, Ed.).

IAEA. 2015. The Fukushima Daiichi accident. Technical Vol.3/5 (Emergency Preparedness and Response). International Atomic Energy Agency.
ICRP. 2007. The 2007 Recommendations of the International Commission on Radiological Protection. ICRP Publ. 103.

Kotoba Dialogues in Fukushima. 2015. The story of four years of dialogue for the rehabilitation of living conditions in the areas contaminated by the Fukushima accident. Web documentary, www.fukushima-dialogues.com.

Kurokawa K, et al. 2012. The Official Report of the Fukushima Nuclear Accident Independent Investigation Commission. The National Diet of Japan Fukushima Nuclear Accident Independent Investigation Commission.

Lochard J, Schneider T, Ando R, Niwa O, Clement C, Lecomte JF, Tada J. 2019. An overview of the dialogue meetings initiated by ICRP in Japan after the Fukushima accident. Radioprotection 54 (2): 87-101.

Maître M, Croüail P, Durand V, Lecomte JF, Charron S, Schneider T. 2020. The management of contaminated goods in Japan since the Fukushima accident. Radioprotection 55(1): 17-28.

Midorikawa S, Tanigawa K, Suzuki S. 2017. Psychosocial issues related to thyroid examination after a radiation disaster. Asia Pac. J. Public Health 29(2S): 63S-73S. APJPH.

Miyazaki M, Hayano R. 2017. Individual external dose monitoring of all citizens of Date City by passive dosimeter 5 to 51 months after the Fukushima NPP accident (series): 1. Comparison of individual dose with ambient dose rate monitored by aircraft surveys. $J$. Radiol. Protect. 37: 1-12.

Miyazaki M, Ohtsuru A, Ishikawa T. 2014. An overview of internal dose estimation using whole-body counters in Fukushima Prefecture. Fukushima J. Med. Sci. 60(1): 95-100.

MOE. 2013. Decontamination Guidelines, 2nd ed. Japan: Ministry of Environment.

MOE. 2014. A compilation of experiences to date on decontamination for the living environment conducted by the Ministry of the Environment. Japan: Ministry of Environment.

Moriyama N, Iwasa H, Tsubokura M, Kuroda Y, Yasumura S. 2019. Living in the restoration public housing after the Great East Japan earthquake correlates with lower subjective well-being of older adults. Int. J. Environ. Public Health 16(15). https://doi.org/ 10.3390/ijerph16152696.

Mosneaga A, Sato A, Turner N. 2016. Fukushima Global Communication Programme Final Report. Tokyo: United Nations University Institute for the Advanced Study of Sustainability (UNU-IAS Reports).

Murakami M, Ono K, Nakatani J. 2015. Perception of radiation risk and willingness to return home following decontamination. $J$. Stage Environ. Sci. 28(3): 193-210.

Murakami M, Tsubokura M, Ono K, Nomura S, Oikawa T. 2017. Additional risk of diabetes exceeds the increased risk of cancer caused by radiation exposure after the Fukushima disaster. PLoS One 12(9): e0185259. https://doi.org/10.1371/journal. pone. 0185259 .

Murakami M, Takebayashi Y, Tsubokura M. 2019. Lower psychological distress levels among returnees compared with evacuees after the Fukushima nuclear accident. Tohoku J. Exp. Med. 247(1): 13-17. https://doi.org/10.1620/tjem.247.13.

Naito W, Uesaka M, Yamada C, Kurosawa T, Yasutaka T, Ishii H. 2016. Relationship between individual external doses, ambient dose rates and individuals' activity-patterns in affected areas in Fukushima following the Fukushima Daiichi nuclear power plant accident. PLoS One 11(8).

Naito W, Uesaka M, Korosawa T, Kuroda Y. 2017. Measuring and assessing individual external doses during the rehabilitation phase in Iitate village after the Fukushima Daiichi nuclear power plant accident. J. Radiol. Protect. 37(3): 606-622. 
National Diet of Japan NAIIC. 2012. The official report of The Fukushima Nuclear Accident Independent Investigation Commission. Tokyo (Japan): National Diet of Japan Fukushima Nuclear Accident Independent Investigation Commission. http://warp.da. ndl.go.jp/info:ndljp/pid/3856371/naiic.go.jp/en/report/index.html.

NERHQ. 2011. Reports of Japanese Government to IAEA Ministerial Conference on Nuclear Safety-Accident at TEPCO's Fukushima Nuclear Power Stations. Tokyo: Nuclear Emergency Response Headquarters Government of Japan.

Nishida S. 2014. IAEA Report on radiation protection after the Fukushima Daiichi accident: Promoting confidence and understanding.

Nomura S, et al. 2013. Mortality risk amongst nursing home residents evacuated after the Fukushima nuclear accident: a retrospective cohort study. PLoS One 8: e60192.

Nomura S, et al. 2015. Comparison between direct measurements and modelled estimates of external radiation exposure among school children 18 to 30 months after the Fukushima nuclear accident in Japan. Environ. Sci. Technol. 49(2): 1009-16.

Nomura S, Murakami M, Naito W, Yasutaka T, Sawano T, Tsubokura M. 2019. Low dose of external exposure among returnees to former evacuation areas: a cross-sectional all-municipality joint study following the 2011 Fukushima Daiichi nuclear power plant incident. J. Radiol. Protect.: Off. J. Soc. Radiol. Protect. 40(1): 1-18.

Orui M, Kuroda Y, Yasumira S. 2019. Suicide rates and mental health measures after the lifting of the evacuation orders following the Fukushima Daiichi nuclear power plant accident: A practical report developed in collaboration with the local municipality (in Japanese). 日本公衆衛生学雑誌 66(8): 407-416.

Oughton D, Albani V, Barquinero F, Chumak V, Clero E, Croüail P, Fattibene P, Kesminiene A, Laurier D, Liutsko L, Ohba T, Ostroumova E, Pirard P, Rogel A, Sarukhan A, Schneider T, Tanigawa K, Tomkiv E, Vale L, Cardis E, on behalf of the SHAMISEN Consortium. 2016. Recommendations and procedures for preparedness and health surveillance of populations affected by a radiation accident. Final report of the SHAMISEN (Nuclear Emergency Situations Improvement of Medical and Health Surveillance) Project. Barcelona: ISGlobal Barcelona Institute for Global Health.

Reconstruction Agency. (2012-2019). Surveys on residents' intention in the municipalities affected by the nuclear accident.

Renaud P, Simon-Cornu M, Gonze MA, Mourlon C, Parache V, Korsakissok I, Navarro E, Cessac B, Rannou A, Champion D. 2014. Contamination of Japanese foodstuffs of terrestrial origin after the Fukushima nuclear accident and related dose assessment. Radioprotection 49(1): 17-22.

Schneider T, Maître M, Lochard J, Charron S, Lecomte JF, Ando R, Kanai Y, Kurihara M, Kuroda J, Miyazaki M, Naito W, Orira M, Takamura N, Tanigawa K, Tsubokura M, Tasutaka T. 2019. The role of radiological protection experts in stakeholder involvement in the recovery phase of post-nuclear accident situations: Some lessons from the Fukushima-Daiichi NPP accident. Radioprotection 54(2): 259-271.

Shimura T, Yamaguchi I, Terada H, Robert Svendsen E, Kunugita N. 2015. Public health activities for mitigation of radiation exposures and risk communication challenges after the Fukushima nuclear accident. J. Radiat. Res. 56(3): 422-429.
Shinkawa T. 2019. Fukushima 8 years after the accident: the current situation of the NPP, surrounding areas, and confidence building. In: Oral Communication (on behalf of METI) at the NEA-OCDE Joint Symposium "Decommissioning, Reconstruction, Rehabilitation, and Food Safety: Rebuilding Post-Accident Confidence" co-organized by OECD/NEA, MAFF (Ministry of Agriculture, Forestry and Fisheries, Japan) and METI (Ministry of Economy, Trade and Industry, Japan), on OECD Conference Centre, Paris, 26 March 2019.

Takahara S, Croüail P, Schneider T. 2017. Implementing optimisation in post-accident situation: some lessons from Fukushima. In: 17th European ALARA Network Workshop, 15-17 May 2017, Lisbon, Portugal

Tanigawa K, Hosoi Y, Hirohashi N, Iwasaki Y, Kamiya K. 2012. Loss of life after evacuations: lessons learned from the Fukushima accident. Lancet 379.

Tsubokura M. 2018. Secondary health issues associated with the Fukushima Daiichi nuclear accident, based on the experiences of Soma and Minamisoma Cities. J. Natl. Inst. Public Health 67(1): 71-83.

Tsubokura M, Hara K, Matsumura T, Sugimoto A. 2014. The immediate physical and mental health crisis in residents proximal to the evacuation zone after Japan's nuclear disaster: An observational pilot study. Disaster Medicine and Public Health Preparedness. Published online by Cambridge University Press.

Tsubokura M, et al. 2015. Assessment of the annual additional effective doses amongst Minamisoma children during the second year after the Fukushima Daiichi nuclear power plant disaster. PloS one 10(6): e0129114.

Tsubokura M, et al. 2017. Individual external doses below the lowest reference level of $1 \mathrm{mSv}$ per year five years after the 2011 Fukushima nuclear accident among all children in Soma City, Fukushima: A retrospective observational study. PloS one 12(2): e0172305.

Wada Y. 2015. Rethinking the meaning of damage and disaster: Incommensurability and power in disputing process. In: The role of law and lawyers for disaster victims: A University of California Hastings-Waseda Symposium on the Legal Aftermath of the Fukushima Daiichi Nuclear Power Station Disaster. Asian Pacific Law Policy J. 16(2): 116-126.

Yasumura S, Goto A, Yamasaki S, Reich MR. 2012. Excess mortality among related institutionalized elderly after the Fukushima nuclear disaster. Public Health.

Yokoshima N. 2019. Post-accident food safety management status. In: Oral communication (on behalf of MAFF) at the OECD-NEA Joint Symposium "Decommissioning, Reconstruction, Rehabilitation, and Food Safety: Rebuilding Post-Accident Confidence" co-organized by OECD/NEA, MAFF (Ministry of Agriculture, Forestry and Fisheries, Japan) and METI (Ministry of Economy, Trade and Industry, Japan), on OECD Conference Centre, Paris, 26 March 2019.

Zhang H, et al. 2014. Radiation-driven migration: the case of Minamisoma City, Fukushima, Japan, after the Fukushima nuclear accident. Int. J. Environ. Res. Public Health 2014(11): 9286-9305. https://doi.org/10.3390/ijerph110909286.

Zheng W, et al. 2017. Longitudinal changes in body mass index of children affected by the Great East Japan Earthquake. Int. J. Obes. 41: 606-612.

Cite this article as: Croüail P, Schneider T, Gariel J-C, Tsubokura M, Naito W, Orita M, Takamura N. 2020. Analysis of the modalities of return of populations to the contaminated territories following the accident at the Fukushima power plant. Radioprotection 55(2): 79-93 


\section{Appendix A.}

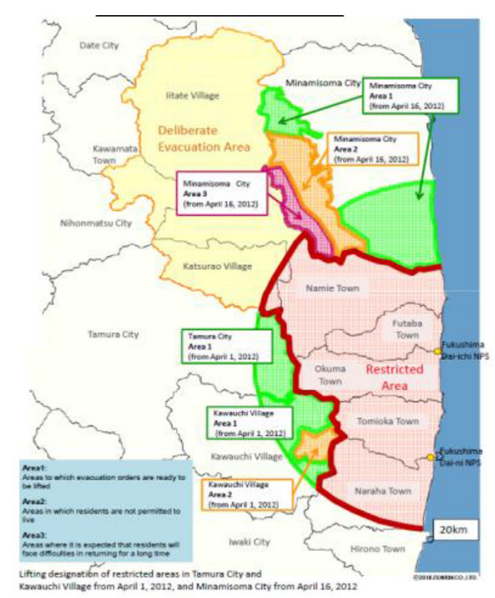

1 April, 2012

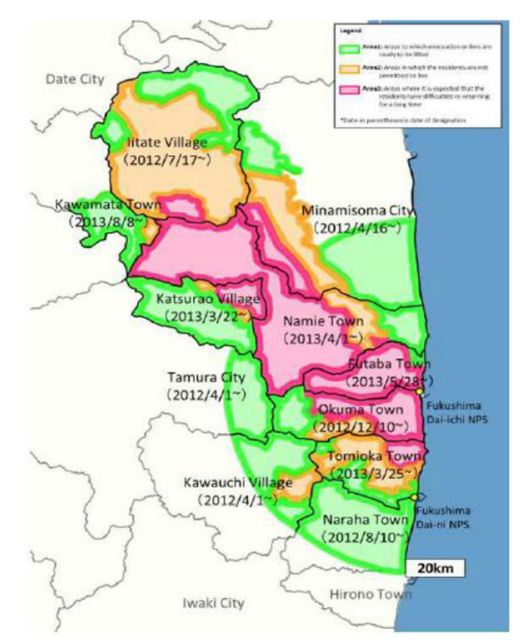

8 August, 2013

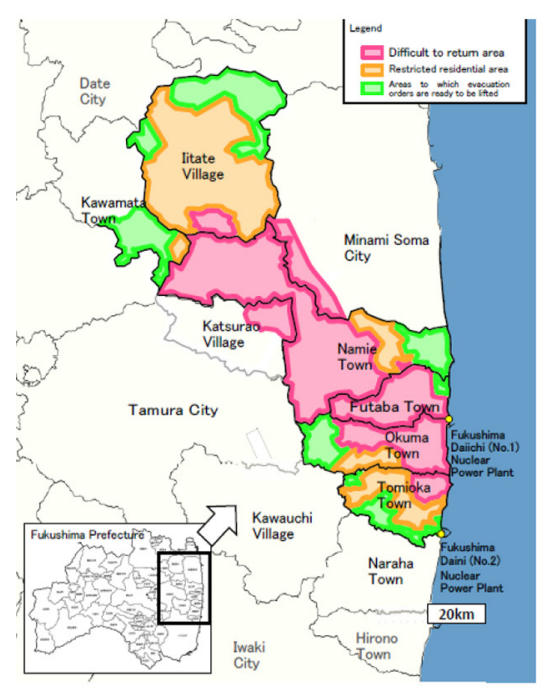

12 July, 2016

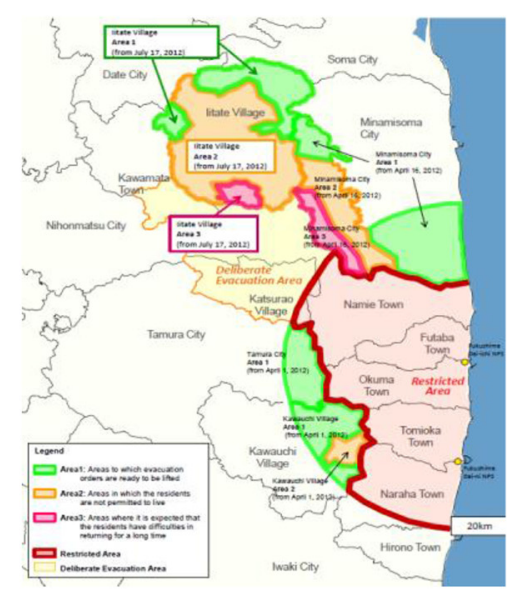

15 June, 2012

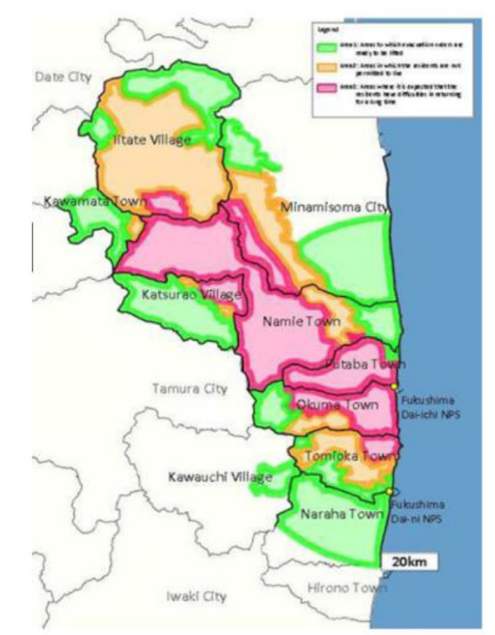

1 October, 2014

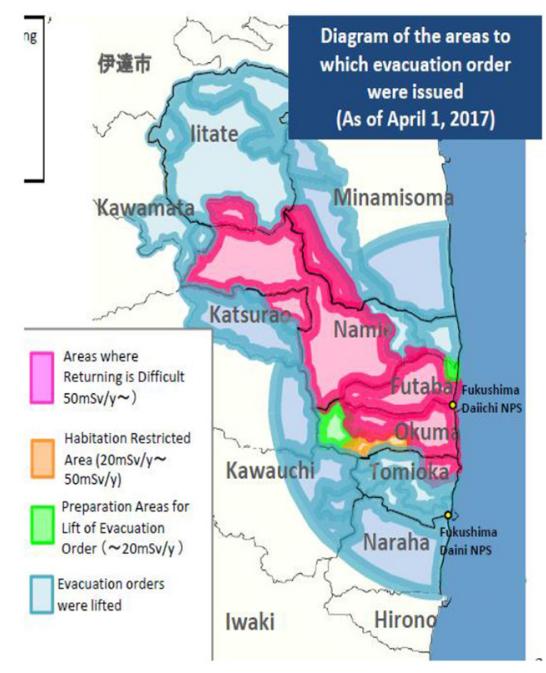

1 April, 2017 (until 2019)

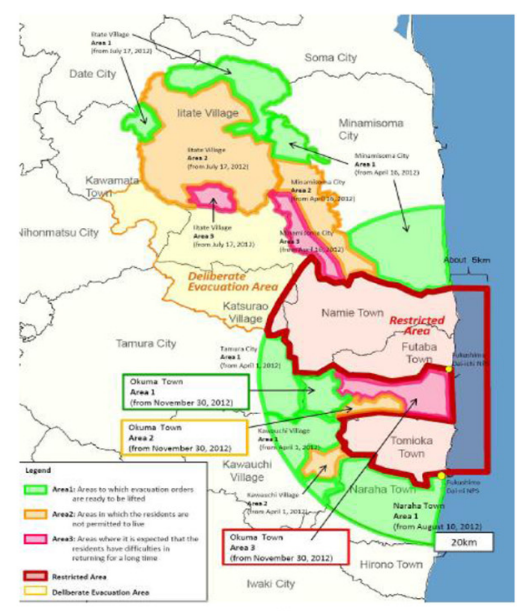

30 November, 2012

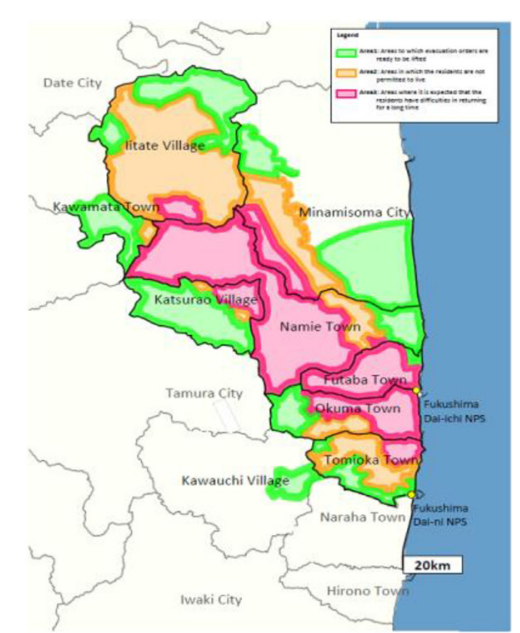

5 September, 2015

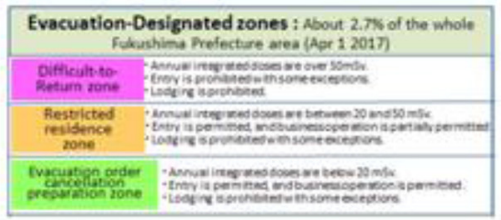

Fig. A1. 2012-2019 Evolution of the Post-Accident Zoning in SDA (Source: Fukushima Prefecture). 